\title{
Association between Dietary Pattern, Lifestyle, Anthropometric Status, and Anemia-Related Biomarkers among Adults: A Population-Based Study from 2001 to 2015
}

\author{
Rathi Paramastri ${ }^{1}$ D, Chien-Yeh Hsu ${ }^{2,3}$, Hsiu-An Lee ${ }^{4,5}$ (D) Li-Yin Lin ${ }^{6}$, Adi Lukas Kurniawan ${ }^{7}$ (D) \\ and Jane C.-J. Chao ${ }^{1,3,8, * \text { D }}$
}

1 School of Nutrition and Health Sciences, College of Nutrition, Taipei Medical University, 250 Wu-Hsing Street, Taipei 11031, Taiwan; rara.paramastri@gmail.com

2 Department of Information Management, National Taipei University of Nursing and Health Sciences, 365 Ming-Te Road, Peitou District, Taipei 11219, Taiwan; cyhsu@ntunhs.edu.tw

3 Master Program in Global Health and Development, College of Public Health, Taipei Medical University, $250 \mathrm{Wu}$-Hsing Street, Taipei 11031, Taiwan

4 Department on Computer Science and Information Engineering, Tamkang University, 151 Yingzhuan Road, Tamsui District, New Taipei 25137, Taiwan; billy72325@gmail.com

5 National Health Research Institutes, 35 Keyan Road, Zhunan Town, Miaoli County 35053, Taiwan

6 School of Public Health, College of Public Health, Taipei Medical University, 250 Wu-Hsing Street, Taipei 11031, Taiwan; jlin11025@gmail.com

check for

updates

Citation: Paramastri, R.; Hsu, C.-Y.; Lee, H.-A.; Lin, L.-Y.; Kurniawan, A.L.; Chao, J.C.-J. Association between Dietary Pattern, Lifestyle, Anthropometric Status, and Anemia-Related Biomarkers among Adults: A Population-Based Study from 2001 to 2015. Int. J. Environ. Res. Public Health 2021, 18, 3438. https:// doi.org/10.3390/ijerph18073438

Academic Editors: Dominika Guzek and Dominika Głąbska

Received: 26 February 2021

Accepted: 22 March 2021

Published: 26 March 2021

Publisher's Note: MDPI stays neutra with regard to jurisdictional claims in published maps and institutional affiliations.

Copyright: (c) 2021 by the authors Licensee MDPI, Basel, Switzerland. This article is an open access article distributed under the terms and conditions of the Creative Commons Attribution (CC BY) license (https:// creativecommons.org/licenses/by/ $4.0 /)$.
7 Research Center for Healthcare Industry Innovation, National Taipei University of Nursing and Health Sciences, 365 Ming-Te Road, Peitou District, Taipei 11219, Taiwan; 8lukas@ntunhs.edu.tw

8 Nutrition Research Center, Taipei Medical University Hospital, 252 Wu-Hsing Street, Taipei 11031, Taiwan

* Correspondence: chenjui@tmu.edu.tw; Tel.: +886-2-2736-1661 (ext. 6548); Fax: +886-2-2736-3112

Abstract: Inadequate dietary intake, poor nutritional status, heavy smoking, and alcohol consumption are associated with the risk of anemia. The objective of this study was to investigate the associations between dietary patterns, lifestyle, nutritional status, and anemia-related biomarkers among adults using a multivariable regression model. Taiwanese adults aged $20-45$ years $(n=118,924$, 43,055 men and 75,869 women) were obtained from the Mei Jau Health Management Institution database, between 2001 and 2015, for data analysis. The anemia-inflammation-related dietary pattern was derived by reduced rank regression analysis. Dietary patterns with high intakes of eggs, meat, organ meats, rice or flour products, fried foods, sugary beverages, and processed foods significantly increased the risk of anemia, and was associated with decreased hemoglobin, hematocrit, and red blood cells, but increased white blood cells and C-reactive protein levels. Moreover, current alcohol drinkers, as well as people who were underweight, overweight, obese, and central obese, were more likely to increase their risk of anemia by $46 \%, 20 \%, 23 \%, 34 \%$, and $28 \%$, respectively. Interestingly, participants who are current or past smokers were inversely associated with risk of anemia. In conclusion, adherence to the anemia-inflammation dietary pattern was associated with an increased risk of anemia in Taiwanese adults. Furthermore, abnormal weight status and alcohol drinking were correlated with an increased risk of anemia.

Keywords: dietary pattern; reduced rank regression; anemia; anthropometric data; lifestyle; adults

\section{Introduction}

Anemia is defined as a condition where hemoglobin $(\mathrm{Hb})$ concentration is less than the requirement, and has been known to be a global health problem with significant adverse health consequences [1]. The clinical definition of anemia by the World Health Organization (WHO) is $\mathrm{Hb} \leq 7.45 \mathrm{mmol} / \mathrm{L}(12 \mathrm{~g} / \mathrm{dL})$ in women and $\mathrm{Hb} \leq 8.07 \mathrm{mmol} / \mathrm{L}$ $(13 \mathrm{~g} / \mathrm{dL})$ in men [2]. Although the most reliable indicator of anemia at the population level is hemoglobin concentration, measurement of this parameter alone cannot determine the cause of anemia [3]. Anemia has affected more than 2 billion people globally, which 
is approximately over a quarter of the world's population [4]. Cohort survey data from National Health and Nutrition Examination Survey, from 2003 to 2012, in the United States showed that the overall prevalence of anemia was $5.6 \%$, and the rate of moderate/severe anemia was $1.5 \%$, where pregnant women were excluded [5]. A repeated cross-sectional survey in rural China among adults aged 18-64 years demonstrated that the prevalence of anemia was $51.5 \%$ and $53.7 \%$ in 2006 and 2008, respectively, and that women had a significantly higher prevalence of anemia than men in any age group in both 2006 and 2008 [1]. A cohort study from January 2012 to January 2013 in rural south-west Uganda showed that the prevalence of anemia was $16.8 \%$ and $17.6 \%$ in men and women aged 50-64 years, respectively [6]. A nutrition and health survey in Taiwan from 2005 to 2008 revealed that the prevalence of anemia was lower than $10 \%$ in men and close to $20 \%$ in women aged $19-44$ years [7].

The previous studies showed that inadequate dietary intake, poor nutritional status, heavy smoking or alcohol consumption, and sleep disturbance or duration, were correlated with iron metabolism or the risk of anemia [6,8-12]. Less fruit intake [6] and those who were underweight [8] were associated with an increased risk of having anemia. However, people who were actively smoking increased $\mathrm{Hb}$ by $0.16-0.37 \mathrm{mmol} / \mathrm{L}(0.26-0.59 \mathrm{~g} / \mathrm{dL})$, depending on the number of cigarettes smoked [9]. A cross-sectional study in Korea between February 2011 and November 2012 found that heavy drinkers aged 49-79 years with $>30 \mathrm{~g} / \mathrm{d}$ alcohol consumption had increased odds of iron overload by $61 \%$ (OR $=1.61$, $95 \%$ CI 1.11, 2.36) compared to non-drinkers [10]. An epidemiological study in the UK reported that people aged $\geq 50$ years with intermediate sleep disturbance were more likely to have anemia (OR $=1.59-1.73,95 \% \mathrm{CI} 1.02-1.13,2.46-2.65)$ compared to those with low sleep disturbance [11]. Additionally, a prospective cohort study in the Kailuan community from June 2006 to October 2007 among Chinese aged $\geq 18$ years revealed that people with sleep durations of $\leq 5 \mathrm{~h}, 6 \mathrm{~h}$, and $\geq 9 \mathrm{~h}$ significantly increased hazard ratios of anemia by $23 \%(\mathrm{HR}=1.23,95 \% \mathrm{CI} 1.04,1.45), 26 \%(\mathrm{HR}=1.26,95 \% \mathrm{CI} 1.11,1.44)$, and $42 \%(\mathrm{HR}=1.42$, $95 \%$ CI 1.08, 1.86), respectively, compared to those with a sleep duration of $7 \mathrm{~h} \mathrm{[12].}$

Current knowledge about the linkage between dietary factors and anemia has mainly focused on individual nutrients. The dietary pattern is currently considered as a new approach to be applied in nutritional epidemiology for the assessment of the association between dietary factors and disease risk [13]. Several previous studies examined the association between overall dietary patterns and anemia by considering how foods and nutrients are consumed in combinations $[14,15]$. However, the study for the relationship between dietary patterns and anemia in adults was still limited in Taiwan. Therefore, we aimed to explore the associations of dietary patterns, lifestyle variables, and anthropometric status with anemia in Taiwanese adults.

\section{Materials and Methods}

\subsection{Data Source and Study Participants}

This study used data between 2001 and 2015 from the Mei Jau (MJ) Health Management Institution, which has four health screening centers located in Taipei, Taoyuan, Taichung, and Kaohsiung, in Taiwan. Subjects who visited the health screening center for health examinations were requested to fill in the self-reported questionnaire for information on sociodemographic data, lifestyles, medical history, and dietary habits, and have anthropometric measurements and blood tests taken, after at least 8-h of fasting, by a trained nurse or medical laboratory technician. All subjects signed a consent form and allowed the MJ Health Management Institution use of their information for research purpose, without personal identification. A total of 118,924 subjects ( 43,055 men and 75,869 women) aged 20-45 years were included in this study for analysis. We excluded those who were pregnant or breast-feeding, and those who had any type of cancer, cirrhosis, lung disease, autoimmune disease, or viral infection (Figure 1). The Joint Institutional Review Board of Taipei Medical University (TMU-JIRB N201907025) approved this study. 


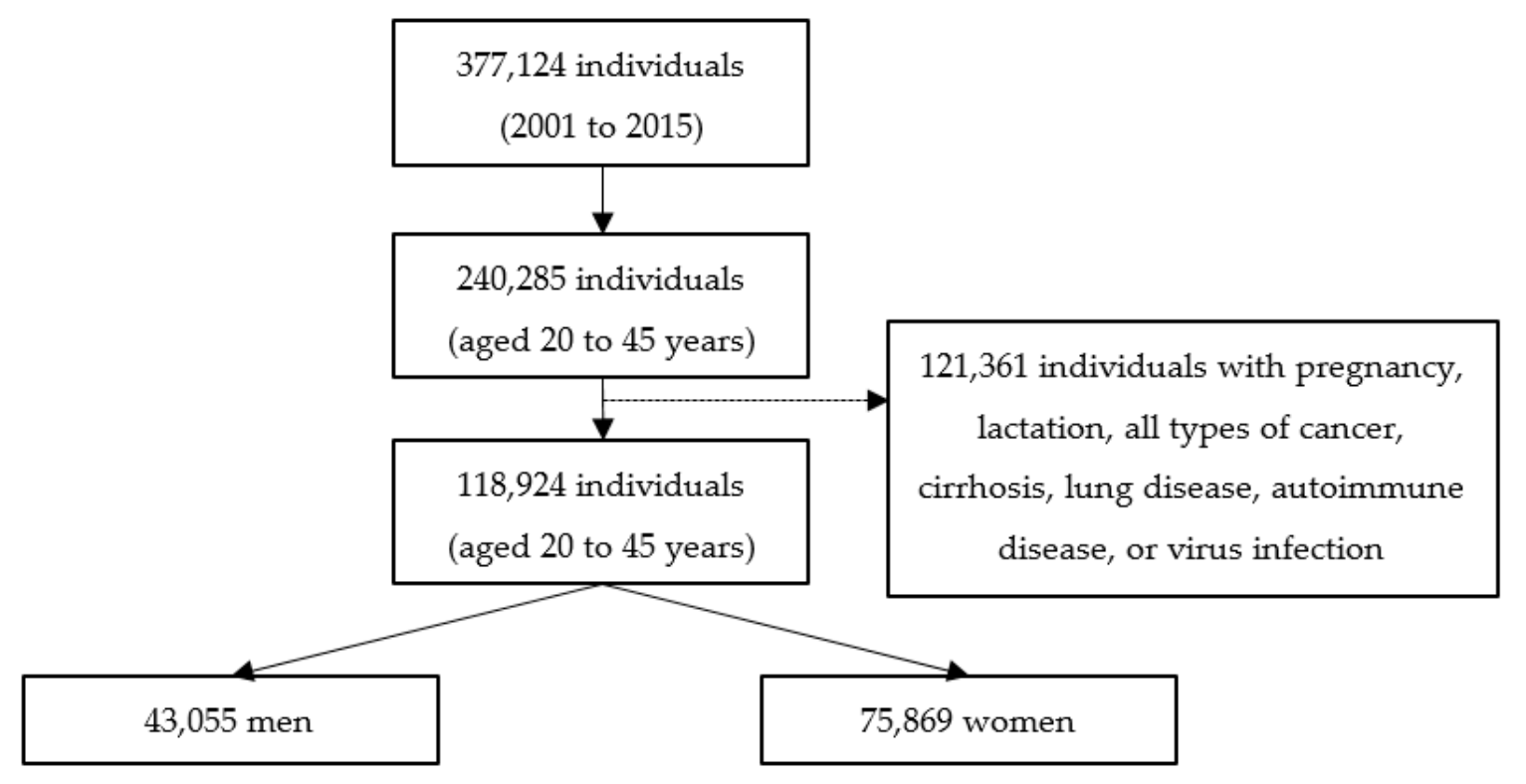

Figure 1. Flowchart of study participants.

\subsection{Anthropometric and Biochemical Data}

The anthropometric data, including body weight, height, and waist and hip circumferences, were retrieved from the database. Body weight and height of the subjects were measured by using an auto-anthropometer (KN-5000A, Nakamura, Tokyo, Japan). Body mass index (BMI) was calculated by $\mathrm{kg} / \mathrm{m} 2$. Weight status is defined by using BMI criteria in Taiwan: underweight (BMI $\left.<18.5 \mathrm{~kg} / \mathrm{m}^{2}\right)$, normal weight $\left(18.5 \mathrm{~kg} / \mathrm{m}^{2} \leq \mathrm{BMI}<24 \mathrm{~kg} / \mathrm{m}^{2}\right)$, overweight $\left(24 \mathrm{~kg} / \mathrm{m}^{2} \leq \mathrm{BMI}<27 \mathrm{~kg} / \mathrm{m}^{2}\right)$, or obese $\left(\mathrm{BMI} \geq 27 \mathrm{~kg} / \mathrm{m}^{2}\right)$ [16]. Waist circumference (WC) was used to define central obesity, with $W C \geq 90 \mathrm{~cm}$ for men and $\geq 80 \mathrm{~cm}$ for women [17]. Biochemical data were analyzed by the central laboratory of the MJ Health Management Institution. Subjects completed blood tests (Abbott Cell-Dyn 3700 hematology analyzer, Abbott Park, IL, USA) when they visited the health screening center for health examinations. Biochemical data, including anemia-related biomarkers such as hemoglobin $(\mathrm{Hb})$, hematocrit (Hct), and red blood cells (RBC), as well as inflammation biomarkers such as white blood cells (WBC) and C-reactive protein (CRP), were retrieved from the database. The level of CRP was measured using an auto-analyzer (Toshiba C8000, Tokyo, Japan). The definition of anemia was based on WHO criteria: $\mathrm{Hb}<8.07 \mathrm{mmol} / \mathrm{L}$ $(13 \mathrm{~g} / \mathrm{dL})$ and $<7.45 \mathrm{mmol} / \mathrm{L}(12 \mathrm{~g} / \mathrm{dL})$ for men and women, respectively [2], and hematocrit level <33\% [18].

\subsection{Dietary Assessment and Other Covariates}

The MJ Health Management Institution had developed a standardized and validated semi-quantitative food frequency questionnaire (FFQ) with 22 food groups, and which was reported in previous studies $[19,20]$. The initial questionnaire comprised 85 closed-ended questions on individual food items, and was further classified into 22 non-overlapping food groups on the basis of presumed health effects and similarity, as described in previous studies [21-23]. Frequency of a fixed serving consumed was assessed per day, or in a week in the past, one month prior to data collection. There were 5 response options for each food group, as described previously [21]. Dietary data were collected for further analysis to derive dietary patterns using a reduced rank regression model. A self-reported questionnaire, including demographic data, lifestyles, and medical history, was used to collect personal information. Demographic and lifestyle characteristics included age, gender, smoking (non-smoker, past smoker, or current smoker), drinking alcohol (no or yes with $\geq 1$ time a week), chewing betel nut (no or yes with $\geq 1$ time a week), sleep duration $(<6 \mathrm{~h}, 6-8 \mathrm{~h}$, or $>8 \mathrm{~h}$ ), and physical activity ( $\leq 2 \mathrm{~h}$ a week or $>2 \mathrm{~h}$ a week). 
Demographic and lifestyle variables were used for association analysis with anemia or anemia-inflammation-related biomarkers, and for the adjusted variables in the models of regression analysis. Medical history included the use of drugs for hypertension, diabetes, cardiovascular disease, or hyperlipidemia.

\subsection{Statistical Analysis}

Statistical analysis was performed using SAS version 9.4 (SAS Institute, Chicago, IL, USA). A Kolmogorov-Smirnov test was performed to determine the distribution of the data. A Mann-Whitney U test was used to compare the differences between two groups. Furthermore, differences among multiple groups were assessed by one-way analysis of variance (ANOVA), followed by a Kruskal-Wallis test. A chi-square test was used to analyze the categorical data. The multivariable logistic regression was performed to identify the risk factors associated with anemia. The multivariable linear regression was conducted to determine the association of dietary patterns, lifestyle, and anthropometric data with anemia-related biomarkers. Dietary pattern was derived by reduced rank regression (RRR) with the PROC PLS function using SAS 9.4, and 22 food groups were used as predictors. We included $\mathrm{Hb}, \mathrm{Hct}, \mathrm{RBC}, \mathrm{WBC}$, and CRP for the response variables (Figure 2). According to previous investigations, we retained all food groups which had the absolute value of factor loading $\geq 0.20$ to derive the dietary patterns associated with anemia $[24,25]$. Then, we calculated dietary factor scores for each food group by summing food frequency intake weighed by their factor loadings. Finally, we only retained the first factor which explained the greatest variation in the response variables. The derived dietary pattern was divided into tertiles according to dietary factor scores. The $p$-value $<0.05$ was considered statistically significant.

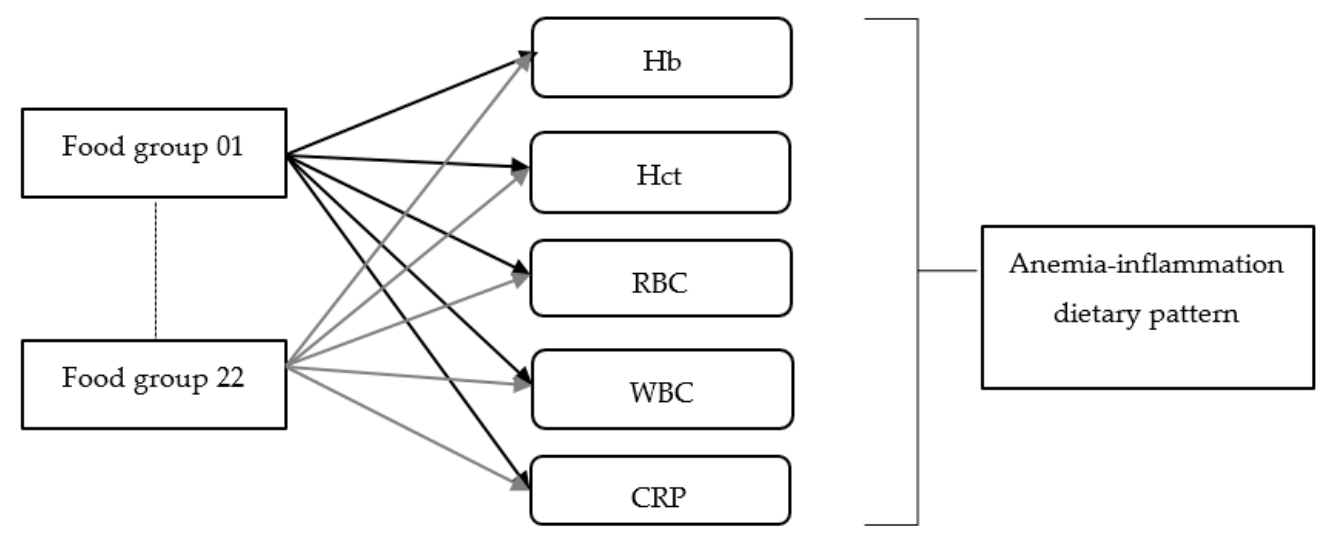

Figure 2. The dietary pattern derived from the reduced rank regression model. Hb: hemoglobin, Hct: hematocrit, RBC: red blood cells, WBC: white blood cells, CRP: C-reactive protein.

\section{Results}

\subsection{Characteristics of the Study Participants}

The characteristics of the subjects are presented in Table 1 . A total of $10.8 \%(n=12,901)$ of the subjects had anemia among all subjects $(n=118,924)$ aged $20-45$ years. The majority of anemic subjects were female $(96.0 \%)$. Women had a higher anemia prevalence than men $(16.3 \%$ vs. $1.2 \%)$. The characteristics of the subjects were more likely to be not smoking, not drinking, not chewing betel nut, having a high proportion of short sleep duration $(<6 \mathrm{~h})$, sedentary activity ( $\leq 2 \mathrm{~h} /$ week), and normal BMI. The prevalence of hypertension and diabetes was $4.6 \%$ and $1.3 \%$, respectively. Anemic subjects were less likely to be current smokers, drinkers, betel nut chewers, suffer from short sleep duration $(<6 \mathrm{~h})$, engage in active physical activity ( $>2 \mathrm{~h} /$ week), have hypertension, be overweight, obese, or have central obesity, and they had worse anemia biomarkers and a higher WBC count compared to those without anemia. 
Table 1. Characteristics of study participants aged $20-45$ years $(n=118,924)^{\mathrm{a}}$.

\begin{tabular}{|c|c|c|c|c|}
\hline Variables & $\begin{array}{l}\text { All Subjects } \\
(n=118,924)\end{array}$ & $\begin{array}{l}\text { Subjects without Anemia } \\
\qquad(n=106,023)\end{array}$ & $\begin{array}{l}\text { Subjects with Anemia } \\
(n=12,901)\end{array}$ & $p$ \\
\hline \multicolumn{5}{|c|}{ Demographic and lifestyle data } \\
\hline Age, years & $33.6 \pm 6.5$ & $33.4 \pm 6.5$ & $35.3 \pm 6.5$ & 0.262 \\
\hline Gender & & & & $<0.001$ \\
\hline Men & $43,055(36.2 \%)$ & $42,543(98.8 \%)^{b}$ & $512(1.2 \%)^{b}$ & \\
\hline Women & $75,869(63.8 \%)$ & $63,480(83.7 \%)^{b}$ & $12,389(16.3 \%)^{b}$ & \\
\hline Smoking & & & & $<0.001$ \\
\hline Non-smoker & $95,733(80.5 \%)$ & $83,842(79.1 \%)$ & $11,891(92.2 \%)$ & \\
\hline Past smoker & $4617(3.9 \%)$ & $4352(4.1 \%)$ & $265(2.1 \%)$ & \\
\hline Current smoker & $18,574(15.6 \%)$ & $17,829(16.8 \%)$ & $745(5.7 \%)$ & \\
\hline Drinking alcohol & & & & $<0.001$ \\
\hline No & $106,721(89.7 \%)$ & $94,461(89.1 \%)$ & $12,260(95.0 \%)$ & \\
\hline Yes & $12,203(10.3 \%)$ & $11,562(10.9 \%)$ & $641(5.0 \%)$ & \\
\hline Chewing betel nut & & & & $<0.001$ \\
\hline No & $118,657(99.8 \%)$ & $105,761(99.8 \%)$ & $12,896(99.9 \%)$ & \\
\hline Yes & $267(0.2 \%)$ & $262(0.2 \%)$ & $5(0.1 \%)$ & \\
\hline Sleep duration & & & & $<0.001$ \\
\hline$<6 \mathrm{~h}$ & $98,970(83.2 \%)$ & $88,358(83.3 \%)$ & $10,612(82.3 \%)$ & \\
\hline $6-8 \mathrm{~h}$ & $19,554(16.4 \%)$ & $17,318(16.3 \%)$ & $2236(17.3 \%)$ & \\
\hline$>8 \mathrm{~h}$ & $400(0.4 \%)$ & $347(0.4 \%)$ & $53(0.4 \%)$ & \\
\hline Physical activity & & & & $<0.001$ \\
\hline$\leq 2 \mathrm{~h} /$ week & $101,809(85.6 \%)$ & $90,347(85.2 \%)$ & $11,462(88.8 \%)$ & \\
\hline$>2 \mathrm{~h} /$ week & $17,115(14.4 \%)$ & $15,676(14.8 \%)$ & $1439(11.2 \%)$ & \\
\hline \multicolumn{5}{|c|}{ Prevalence of chronic diseases } \\
\hline Hypertension & $5446(4.6 \%)$ & $5058(4.8 \%)$ & $388(3.0 \%)$ & $<0.001$ \\
\hline Diabetes & $1538(1.3 \%)$ & $1378(1.3 \%)$ & $160(1.2 \%)$ & 0.258 \\
\hline \multicolumn{5}{|c|}{ Anthropometric measurements } \\
\hline Body mass index, $\mathrm{kg} / \mathrm{m}^{2 \mathrm{c}}$ & & & & $<0.001$ \\
\hline Underweight & $14,333(12.1 \%)$ & $12,414(11.7 \%)$ & $1919(14.9 \%)$ & \\
\hline Normal & $72,838(61.3 \%)$ & $63,965(60.3 \%)$ & $8873(68.8 \%)$ & \\
\hline Overweight & $20,348(17.1 \%)$ & $18,902(17.8 \%)$ & $1446(11.2 \%)$ & \\
\hline Obese & $11,405(9.5 \%)$ & $10,742(10.2 \%)$ & $663(5.1 \%)$ & \\
\hline Central obesity $^{\mathrm{d}}$ & $12,981(10.9 \%)$ & $12,048(11.4 \%)$ & $933(0.9 \%)$ & $<0.001$ \\
\hline \multicolumn{5}{|c|}{ Anemia or inflammatory biomarkers } \\
\hline Hemoglobin, mmol/L & $8.6 \pm 1.1$ & $8.8 \pm 0.8$ & $6.8 \pm 0.7$ & $<0.001$ \\
\hline Hematocrit, \% & $41.1 \pm 4.6$ & $41.9 \pm 3.8$ & $33.7 \pm 2.9$ & $<0.001$ \\
\hline Red blood cells, $10^{6} / \mu \mathrm{L}$ & $4.7 \pm 0.5$ & $4.7 \pm 0.5$ & $4.5 \pm 0.6$ & $<0.001$ \\
\hline White blood cells, $10^{3} / \mu \mathrm{L}$ & $6.0 \pm 1.7$ & $5.6 \pm 2.2$ & $6.1 \pm 1.6$ & $<0.001$ \\
\hline C-reactive protein, $\mathrm{nmol} / \mathrm{L}$ & $18.8 \pm 34.7$ & $18.7 \pm 40.5$ & $18.9 \pm 33.9$ & 0.130 \\
\hline
\end{tabular}

${ }^{a}$ Continuous data are presented as mean $\pm \mathrm{SD}$, and categorical data are presented as number (percentage). The $p$-value was analyzed using a Mann-Whitney $\mathrm{U}$ test for continuous variables, and a chi-square test for categorical variables. ${ }^{\mathrm{b}}$ Percentages were calculated between those with and without anemia in the same gender. ${ }^{c}$ Categories of body mass index, underweight: $<18.5 \mathrm{~kg} / \mathrm{m}^{2}$, normal: $18.5-23.9 \mathrm{~kg} / \mathrm{m}^{2}$, overweight: $24.0-26.9 \mathrm{~kg} / \mathrm{m}^{2}$, obese: $\geq 27 \mathrm{~kg} / \mathrm{m}^{2}$. ${ }^{\mathrm{d}}$ Waist circumference $\geq 90 \mathrm{~cm}$ for men and $\geq 80 \mathrm{~cm}$ for women. 


\subsection{Anemia-Inflammation Dietary Pattern}

The RRR model identified one specific dietary pattern related to anemia. The anemiainflammation-related dietary pattern with absolute factor loadings of $\geq 0.20$ was characterized by high intakes of eggs, meat, organ meats, rice or flour products, fried rice or flour, sugary beverages, fried foods, and processed foods (Figure 3 ). The first factor derived by RRR explained $6.2 \%$ of $\mathrm{Hb}, 6.1 \%$ of $\mathrm{Hct}, 5.2 \%$ of RBC, $1.2 \% \mathrm{WBC}, 0.1 \% \mathrm{CRP}$, and $8.6 \%$ of the total variation in 5 response variables.

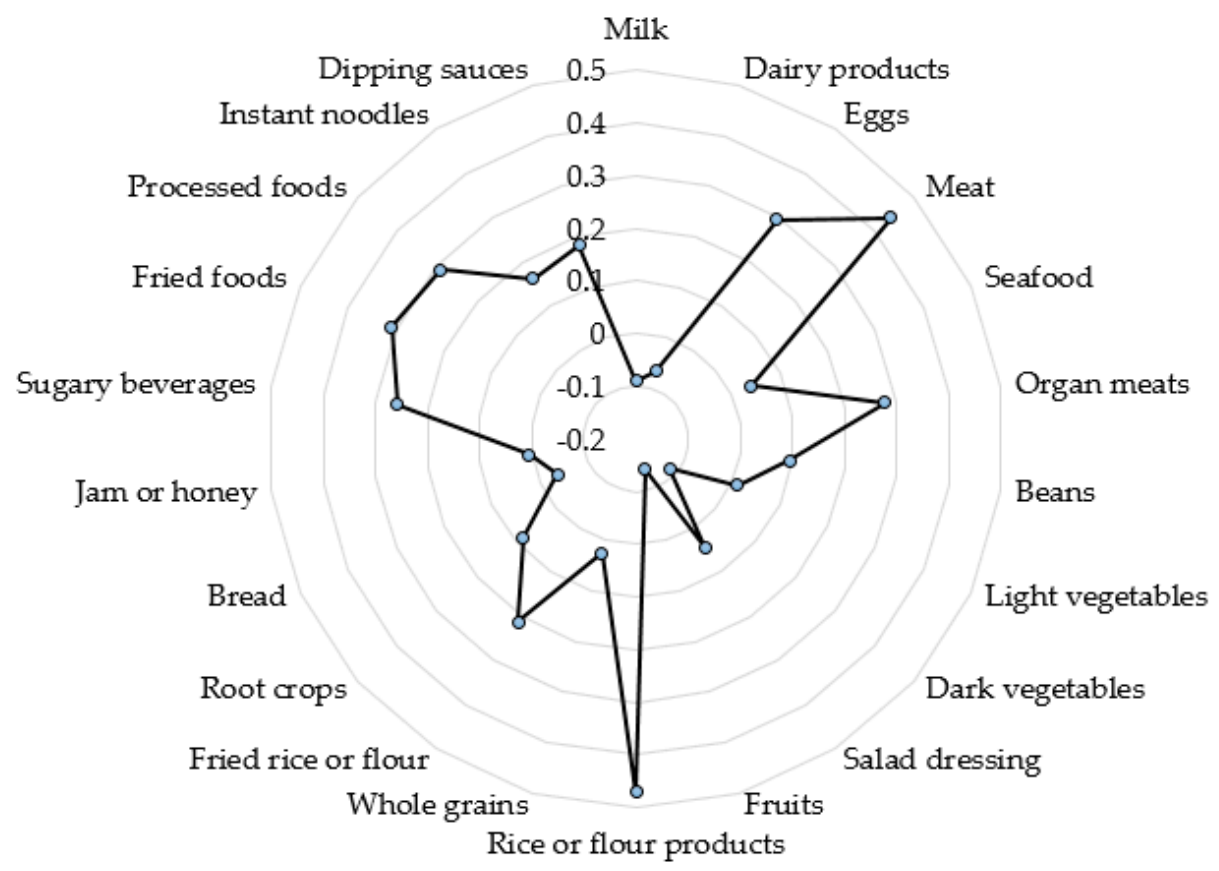

Figure 3. Spider web diagram of anemia-inflammation-related dietary pattern with factor loadings.

\subsection{Association of Lifestyle and Anthropometric Data with Anemia}

Table 2 demonstrated the association of lifestyle and anthropometric data, with anemia analyzed by the multivariable logistic regression. In the unadjusted model, smoking was negatively associated with anemia $(\mathrm{OR}=0.29,95 \% \mathrm{CI} 0.27,0.32$ for past smokers; $\mathrm{OR}=0.43$, $95 \%$ CI 0.38, 0.49 for current smokers). However, drinking alcohol (OR $=2.55,95 \%$ CI 2.31, $2.81)$ and inactive physical activity $(\mathrm{OR}=1.38,95 \% \mathrm{CI} 1.31,1.46)$ were positively associated with anemia. After adjusting for age, gender, hypertension, and diabetes, smoking and drinking alcohol remained significantly associated with anemia. Subjects who were past or current smokers decreased the risk of anemia by $32 \%$ (OR $=0.68,95 \%$ CI $0.63,0.74)$ or $26 \%$ $(\mathrm{OR}=0.74,95 \% \mathrm{CI} 0.64,0.86)$, respectively. By contrast, active alcohol drinkers increased the risk of anemia by $46 \%$ compared to those who were non-drinkers (OR $=1.46,95 \% \mathrm{CI}$ $1.32,1.61)$.

The multivariable logistic regression showed that abnormal BMI was positively associated with the risk of anemia in both crude and adjusted models (Table 2). After adjusting for the full model (model 2), subjects who were underweight $(\mathrm{OR}=1.20,95 \% \mathrm{CI} 1.10$, $1.42)$, overweight $(\mathrm{OR}=1.23,95 \% \mathrm{CI} 1.10,1.38)$, or obese $(\mathrm{OR}=1.34,95 \% \mathrm{CI} 1.22,1.48)$ significantly increased the risk of anemia by $20 \%, 23 \%$, or $34 \%$, respectively, compared to those with normal BMI. Additionally, subjects with central obesity increased the risk of anemia by $28 \%(\mathrm{OR}=1.28,95 \%$ CI 1.18, 1.39) in model 2 .

\subsection{Association between Lifestyle, Anthropometric Data, and Anemia-Related Biomarkers}

Table 3 illustrated the associations between lifestyle, anthropometric data, and anemia or inflammation-related biomarkers. Subjects who had a history of smoking increased $\mathrm{Hb}$ level $(\beta=0.18,95 \%$ CI $0.17,0.19, p<0.05)$ and WBC count $(\beta=0.13,95 \%$ CI 0.07 , 
$0.19, p<0.001)$ compared to those who were non-smokers. Similarly, subjects who were current smokers had higher $\mathrm{Hb}, \mathrm{Hct}, \mathrm{WBC}$, and CRP levels $(p<0.001)$. However, alcohol drinkers showed decreased $\mathrm{Hb}$ levels $(\beta=-0.08,95 \% \mathrm{CI}-0.09,-0.06, p<0.001)$ and RBC count $(\beta=-0.05,95 \% \mathrm{CI}-0.05,-0.04, p<0.001)$ compared to non-drinkers. Short sleep duration $(<6 \mathrm{~h})$ decreased $\mathrm{Hb}$ level $(\beta=-0.02,95 \% \mathrm{CI}-0.03,-0.01, p<0.05)$ and increased WBC count $(\beta=0.28,95 \% \mathrm{CI} 0.03,0.53, p<0.05)$ compared to normal sleep duration $(6-8 \mathrm{~h})$, while long sleep duration $(>8 \mathrm{~h})$ did not show any significant associations with anemia or inflammation-related biomarkers. Subjects who were physically inactive ( $>2 \mathrm{~h} /$ week) had lower $\mathrm{Hb}$, Hct, and RBC levels (all $p<0.001$ ), but higher WBC and CRP levels (all $p<0.05)$ compared to those with active physical activity ( $>2 \mathrm{~h} /$ week). Being underweight was negatively associated with RBC and WBC counts (both $p<0.001$ ). Being overweight, obese, or having central obesity was negatively correlated with anemia-related biomarkers, but positively associated with inflammation biomarkers (all $p<0.001$ ).

Table 2. Odds ratios and 95\% confidence intervals for the associations between lifestyle, anthropometric variables, and anemia ${ }^{a}$.

\begin{tabular}{|c|c|c|c|c|}
\hline & \multicolumn{2}{|c|}{ Model 1} & \multicolumn{2}{|c|}{ Model 2} \\
\hline & OR (95\% CI) & $p$ & OR (95\% CI) & $p$ \\
\hline \multicolumn{5}{|c|}{ Lifestyle } \\
\hline \multicolumn{5}{|l|}{ Smoking (ref: non-smoker) } \\
\hline Past smoker & $0.29(0.27,0.32)$ & 0.001 & $0.68(0.63,0.74)$ & 0.001 \\
\hline Current smoker & $0.43(0.38,0.49)$ & 0.001 & $0.74(0.64,0.86)$ & 0.001 \\
\hline Drinking alcohol (ref: no drinking) & $2.55(2.31,2.81)$ & 0.001 & $1.46(1.32,1.61)$ & 0.001 \\
\hline \multicolumn{5}{|l|}{ Sleep duration (ref: $6-8 \mathrm{~h}$ ) } \\
\hline Short sleep duration $(<6 \mathrm{~h})$ & $1.22(0.91,1.62)$ & 0.188 & $1.12(0.83,1.50)$ & 0.695 \\
\hline Long sleep duration (>8 h) & $1.04(0.98,1.19)$ & 0.140 & $1.01(0.96,1.07)$ & 0.468 \\
\hline Inactive physical activity ${ }^{\mathrm{b}}$ (ref: $>2 \mathrm{~h} /$ week) & $1.38(1.31,1.46)$ & 0.001 & $0.97(0.89,1.05)$ & 0.433 \\
\hline \multicolumn{5}{|c|}{ Anthropometric measurements } \\
\hline \multicolumn{5}{|l|}{ Body mass index ${ }^{\mathrm{c}}$ (ref: normal) } \\
\hline Underweight & $2.58(2.33,2.88)$ & 0.001 & $1.20(1.10,1.42)$ & 0.001 \\
\hline Overweight & $1.24(1.11,1.38)$ & 0.001 & $1.23(1.10,1.38)$ & 0.001 \\
\hline Obese & $2.27(2.07,2.49)$ & 0.001 & $1.34(1.22,1.48)$ & 0.001 \\
\hline Central obesity ${ }^{\mathrm{d}}$ (ref: normal) & $1.64(1.51,1.77)$ & 0.001 & $1.28(1.18,1.39)$ & 0.001 \\
\hline
\end{tabular}

${ }^{\mathrm{a}}$ Model 1 was unadjusted. Model 2 was adjusted for age, gender, hypertension, and diabetes. ${ }^{\mathrm{b}}$ Physical activity $\leq 2 \mathrm{~h} /$ week. ${ }^{\mathrm{c}}$ Categories of body mass index, underweight: $<18.5 \mathrm{~kg} / \mathrm{m}^{2}$, normal: $18.5-23.9 \mathrm{~kg} / \mathrm{m}^{2}$, overweight: $24.0-26.9 \mathrm{~kg} / \mathrm{m}^{2}$, obese: $\geq 27 \mathrm{~kg} / \mathrm{m}^{2}$. ${ }^{\mathrm{d}}$ Waist circumference $\geq 90 \mathrm{~cm}$ for men and $\geq 80 \mathrm{~cm}$ for women.

\subsection{Association between Dietary Pattern, Anemia, and Anemia-Related Biomarkers}

The associations between dietary patterns across tertiles and the risk of anemia, or anemia-related biomarkers, are shown in Table 4. Subjects in the highest tertile (T3) of the dietary pattern increased the risk of anemia by $87 \%(\mathrm{OR}=1.87,95 \% \mathrm{CI} 1.78,1.95, p<0.001)$ in the crude model (model 1) compared to those in the lowest tertile (T1) of the dietary pattern. After adjusting for age, gender, lifestyle, history of chronic diseases, and weight status (model 3), subjects in the highest tertile of the dietary pattern increased the risk of anemia by $59 \%(\mathrm{OR}=1.59,95 \%$ CI 1.51, 1.67, $p<0.001)$. In addition, subjects in the highest tertile of the dietary pattern had worse anemia biomarkers and increased WBC and CRP levels (all $p<0.001$ ), in all the models, compared to those in the lowest tertile of the dietary pattern. 
Table 3. Multivariable regression models for associations between lifestyle, anthropometric variables, and anemia-inflammation-related biomarkers ${ }^{\text {a }}$.

\begin{tabular}{|c|c|c|c|c|c|}
\hline & $\begin{array}{c}\mathrm{Hb}(\mathrm{mmol} / \mathrm{L}) \\
\beta(95 \% \mathrm{CI})\end{array}$ & $\begin{array}{c}\text { Hct (\%) } \\
\beta(95 \% \text { CI) }\end{array}$ & $\begin{array}{c}\mathrm{RBC}\left(10^{6} / \mu \mathrm{L}\right) \\
\beta(95 \% \mathrm{CI})\end{array}$ & $\begin{array}{c}\text { WBC }\left(10^{3} / \mu \mathrm{L}\right) \\
\beta(95 \% \mathrm{CI})\end{array}$ & $\begin{array}{c}\mathrm{CRP}(\mathrm{nmol} / \mathrm{L}) \\
\beta(95 \% \mathrm{CI})\end{array}$ \\
\hline \multicolumn{6}{|c|}{ Lifestyle } \\
\hline \multicolumn{6}{|l|}{ Smoking (ref: non-smoker) } \\
\hline Past smoker & $0.18(0.17,0.19) *$ & $0.09(-0.10,0.20)$ & $-0.00(-0.02,0.01)$ & $0.13(0.07,0.19)^{* *}$ & $-0.29(-1.51,0.91)$ \\
\hline Current smoker & $0.29(0.28,0.32) * *$ & $0.74(0.68,0.80)^{* *}$ & $0.00(-0.01,0.01)$ & $0.68(0.65,0.71)^{* *}$ & $1.21(0.52,1.89)^{* *}$ \\
\hline Drinking alcohol (ref: no drinking) & $-0.08(-0.09,-0.06)^{* *}$ & $0.06(-0.01,0.13)$ & $-0.05(-0.05,-0.04)^{* *}$ & $-0.02(-0.06,0.02)$ & $0.35(-0.42,1.13)$ \\
\hline \multicolumn{6}{|l|}{ Sleep duration (ref: 6-8 h) } \\
\hline Short sleep duration $(<6 \mathrm{~h})$ & $-0.02(-0.03,-0.01) *$ & $-0.03(-0.08,0.02)$ & $0.00(-0.03,0.04)$ & $0.28(0.03,0.53) *$ & $2.31(-3.15,7.77)$ \\
\hline Long sleep duration $(>8 \mathrm{~h})$ & $-0.03(-0.10,0.04)$ & $-0.03(-0.33,0.27)$ & $0.00(-0.00,0.01)$ & $0.02(-0.05,0.01)$ & $-0.24(-0.92,0.43)$ \\
\hline Inactive physical activity ${ }^{b}$ (ref: $>2 \mathrm{~h} /$ week) & $-0.01(-0.02,-0.01) * *$ & $-0.33(-0.39,-0.26)^{* *}$ & $-0.03(-0.03,-0.02) * *$ & $0.14(0.11,0.17) *$ & $1.17(0.55,1.79) *$ \\
\hline \multicolumn{6}{|c|}{ Anthropometric measurements } \\
\hline \multicolumn{6}{|l|}{ Body mass index ${ }^{c}$ (ref: normal) } \\
\hline Underweight & $-0.02(-0.03,0.01)$ & $-0.22(-0.91,0.72)$ & $-0.22(-0.20,-0.23)^{* *}$ & $-0.25(-0.28,-0.22)^{* *}$ & $0.77(-0.14,1.59)$ \\
\hline Obese & $-0.13(-0.15,-0.11)^{* *}$ & $-0.86(-0.93,-0.78)^{* *}$ & $-0.09(-0.10,-0.08) * *$ & $0.73(0.68,0.78)^{* *}$ & $9.58(8.43,10.70)^{* *}$ \\
\hline Central obesity ${ }^{\mathrm{d}}$ (ref: normal) & $-0.14(-0.15,-0.12) * *$ & $-0.78(-0.84,-0.71)^{* *}$ & $-0.06(-0.07,-0.05) * *$ & $0.35(0.31,0.39)^{* *}$ & $9.60(8.67,10.53) * *$ \\
\hline
\end{tabular}

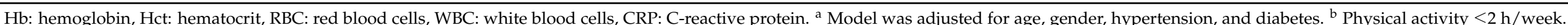

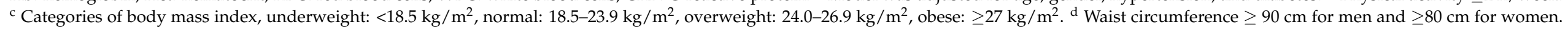

${ }^{*} p<0.05$. ${ }^{* *} p<0.001$. 
Table 4. Associations between tertiles of dietary pattern, anemia, and anemia-related biomarkers among adults in Taiwan ${ }^{\text {a }}$.

\begin{tabular}{|c|c|c|c|c|c|c|}
\hline & \multirow{2}{*}{$\begin{array}{c}\text { Anemia } \\
\text { OR }(95 \% \text { CI })\end{array}$} & \multicolumn{5}{|c|}{ Anemia-Related Biomarkers } \\
\hline & & $\begin{array}{c}\mathrm{Hb}(\mathrm{mmol} / \mathrm{L}) \\
\beta(95 \% \mathrm{CI})\end{array}$ & $\begin{array}{c}\text { Hct (\%) } \\
\beta(95 \% \mathrm{CI})\end{array}$ & $\begin{array}{c}\mathrm{RBC}\left(10^{6} / \mu \mathrm{L}\right) \\
\beta(95 \% \mathrm{CI})\end{array}$ & $\begin{array}{c}\text { WBC }\left(10^{3} / \mu \mathrm{L}\right) \\
\beta(95 \% \mathrm{CI})\end{array}$ & $\begin{array}{c}\text { CRP (nmol/L) } \\
\beta(95 \% \text { CI })\end{array}$ \\
\hline \multicolumn{7}{|c|}{ Model 1 (ref: T1) } \\
\hline $\mathrm{T} 2$ & $1.43(1.36,1.50) * *$ & $-0.26(-0.28,-0.24)^{* *}$ & $-1.19(-1.26,-1.13)^{* *}$ & $-0.12(-0.13,-0.12)^{* *}$ & $0.19(0.17,0.22) * *$ & $0.09(0.09,1.2)^{* *}$ \\
\hline T3 & $1.87(1.78,1.95)^{* *}$ & $-0.48(-0.49,-0.46)^{* *}$ & $-2.21(-2.27,-2.15)^{* *}$ & $-0.23(-0.24,-0.23) * *$ & $0.34(0.29,0.41)^{* *}$ & $1.90(1.59,2.60) * *$ \\
\hline \multicolumn{7}{|c|}{ Model 2 (ref: T1) } \\
\hline T3 & $1.10(1.00,1.23)^{* *}$ & $-0.24(-0.26,-0.24)^{* *}$ & $-0.24(-0.24,-0.09)^{* *}$ & $-0.03(-0.03,-0.02)^{* *}$ & $0.17(0.17,0.21)^{* *}$ & $1.70(1.12,2.37) * *$ \\
\hline \multicolumn{7}{|c|}{ Model 3 (ref: T1) } \\
\hline $\mathrm{T} 2$ & $1.30(1.27,1.41)^{* *}$ & $-0.01(-0.02,-0.00)^{* *}$ & $-0.01(-0.10,-0.01)^{* *}$ & $-0.01(-0.01,-0.00)^{* *}$ & $0.04(0.01,0.07) * *$ & $0.64(0.19,0.89) * *$ \\
\hline T3 & $1.59(1.51,1.67)^{* *}$ & $-0.03(-0.04,-0.02)^{* *}$ & $-0.04(-0.01,-0.09)^{* *}$ & $-0.02(-0.03,-0.02)^{* *}$ & $0.08(0.05,0.10) * *$ & $1.64(0.50,2.21)^{* *}$ \\
\hline
\end{tabular}

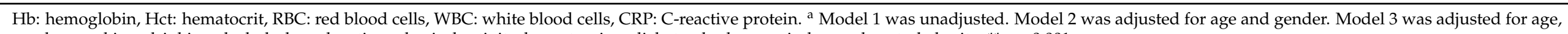
gender, smoking, drinking alcohol, sleep duration, physical activity, hypertension, diabetes, body mass index, and central obesity. ${ }^{* *} p<0.001$. 


\section{Discussion}

\subsection{Lifestyle and Anemia}

Our study found that past or current smokers decreased the risk of anemia, and current smokers were more likely to increase $\mathrm{Hb}$ and Hct levels. Similarly, the previous studies showed that smoking was negatively correlated with the risk of anemia [26-28]. The multiple logistic regression analysis from the health check-up database of St. Luke's international hospital in Tokyo, between April 2016 and March 2017, revealed that Japanese women (35-49 years) who were past or current smokers decreased the risk of anemia by $33 \%(\mathrm{OR}=0.67,95 \%$ CI $0.56,0.81, p<0.001)$ or $25 \%(\mathrm{OR}=0.75,95 \%$ CI $0.56,0.99$, $p=0.045)$, respectively, compared to those who were non-smokers, after adjusting for the covariates [26]. However, the association between past or current smoking and anemia was not statistically significant in Japanese women aged 20-34 years, in both unadjusted and adjusted models [26]. A previous study in India found that male smokers aged 30-60 years had significantly higher $\mathrm{Hb}$, Hct, and RBC levels compared to male nonsmokers [27]. Additionally, an increase in the severity of smoking in adult male smokers showed significantly increased $\mathrm{Hb}, \mathrm{RBC}$, mean corpuscular volume, and mean corpuscular $\mathrm{Hb}$ concentration [28]. The pack-years of smoking were also positively correlated with $\mathrm{Hb}(r=0.418, p<0.001)$ and RBC levels $(r=0.215, p=0.03)$ in adult male smokers [28]. Although this finding should not be interpreted as an alternative approach to decrease the risk of anemia, the cut-off value for $\mathrm{Hb}$ should be adjusted to diagnose anemia in smokers; this is because the $\mathrm{Hb}$ distribution curve shows an upward shift with smoking [29,30]. The WHO released a guideline for the definition of anemia by $\mathrm{Hb}$ cut-off values, with adjustment for smoking and altitude, in 2001 [2]. Increased $\mathrm{Hb}$ in smokers was associated with elevated carboxyhemoglobin ( $\mathrm{HbCO}$ ), a stable complex of $\mathrm{Hb}$ and carbon monoxide (CO), because of exposure to excess $\mathrm{CO}$ caused by smoking [29]. The form of $\mathrm{HbCO}$ decreases oxygen delivery, and smokers had elevated $\mathrm{Hb}$ as a compensatory mechanism to increase erythropoiesis rate and maintain oxygen transportation $[27,30]$. This might explain why adaption to excess $\mathrm{CO}$ during smoking was reflected by the rise in $\mathrm{Hb}$ and RBC mass [31]. Furthermore, increased $\mathrm{Hb}$ and RBC could be responsible for an elevation of Hct levels in smokers [27].

Our findings showed that alcohol drinking increased the risk of anemia, and was correlated with reduced $\mathrm{Hb}$ and RBC levels. Consistent with our results, the previous studies demonstrated a positive correlation between alcohol drinking and anemia [32,33]. A case study in the UK observed that a 56-year-old type 2 diabetic male with chronic alcohol abuse for more than 10 years experienced severe anemia [32]. A previous study in India found that subjects aged $\geq 18$ years with moderate (alcohol $<11$ drinks/day) to severe intakes (alcohol $\geq 11$ drinks/day) of alcohol had lower $\mathrm{Hb}, \mathrm{RBC}$, and mean corpuscular $\mathrm{Hb}$ concentrations $(p<0.001)$ compared to those who did not drink alcohol [33]. However, Japanese women (20-49 years) who were habitual drinkers decreased the risk of anemia by $27 \%-33 \%$ (20-34-year women: OR $=0.67,95 \%$ CI $0.48,0.92, p=0.015,35-49$-year women: $\mathrm{OR}=0.73,95 \% \mathrm{CI} 0.64,0.83, p<0.001)$ compared to those who were non-drinkers, after adjusting for the covariates [28]. The direct causality of this negative correlation between alcohol drinking and anemia, in the previous study, is still unclear. Heavy alcohol consumption can decrease the number of RBC precursors in bone marrow, and generally affect the formation of functional $\mathrm{RBC}$ by interfering with the maturation of $\mathrm{RBC}[34,35]$. The presence of defective RBC by exposure to excess alcohol can contribute to anemia in alcoholic individuals [35].

\subsection{Anthropometric Data and Anemia}

In our study, all abnormal weight statuses, including underweight, overweight, obesity, and central obesity, were linearly associated with an increased risk of anemia. The present study suggested that being underweight was only associated with decreased levels of RBC and WBC in the multivariable-adjusted model. The findings are in concordance with the previous studies $[8,36]$. A cross-sectional study in India showed that undergradu- 
ate medical students who were underweight (BMI $<18 \mathrm{~kg} / \mathrm{m}^{2}$ ) increased the risk of anemia by 7.07-fold compared to those with normal BMI $\left(18.0-22.9 \mathrm{~kg} / \mathrm{m}^{2}\right)$, after adjusting for the covariates (OR $=7.07,95 \% \mathrm{CI} 1.34,37.26, p=0.021)$ [8]. Additionally, a multivariate logistic regression revealed that severely underweight women (BMI $\leq 17.5 \mathrm{~kg} / \mathrm{m}^{2}$ ) aged 20-39 years in Aichi, Japan, were more likely to increase the risk of low lymphocytes $(<1500 / \mu \mathrm{L})$ compared to those with normal BMI $\left(18.5-24.9 \mathrm{~kg} / \mathrm{m}^{2}\right)(\mathrm{OR}=1.95,95 \%$ CI 1.07, $3.56, p=0.03$ ) [36]. Young women aged 16-35 years who were underweight (16-20 years: $\mathrm{BMI}<5$ th percentile, $21-35$ years: $\mathrm{BMI}<18.5 \mathrm{~kg} / \mathrm{m}^{2}$ ) in a rural area of East Java, Indonesia, did not significantly increase the risk of anemia (OR $=2.34,95 \%$ CI $0.97,5.67, p=0.060)$, but were more likely to have iron depletion (OR $=5.88,95 \% \mathrm{CI} 2.02,17.09, p=0.001)$ and iron-deficient erythropoiesis ( $\mathrm{OR}=4.52,95 \% \mathrm{CI} 1.77,11.54, p=0.002)$ compared to those who were not underweight [37]. Our study observed that being overweight, obese, and having central obesity were correlated with increased odds of anemia, as well as decreased $\mathrm{Hb}$, Hct, and RBC levels but increased WBC and CRP levels. However, the previous study showed that overweight Japanese women (BMI: $25.0-29.9 \mathrm{~kg} / \mathrm{m}^{2}$ ) aged 35-49 years were more likely to have a reduced risk of anemia $(\mathrm{OR}=0.74,95 \% \mathrm{CI} 0.59,0.92, p=0.007)$ compared to those with normal BMI $\left(18.5-24.9 \mathrm{~kg} / \mathrm{m}^{2}\right)$; there was no significant association between obesity and anemia [26].

The associations between being overweight, obese, or having central obesity and anemia could be explained by the rise of inflammatory activity in adipose tissue in relation to impaired iron homeostasis in overweight/obese individuals [38]. Increased inflammatory cytokines in overweight or obese individuals could elevate hepcidin, which binds to cellular ferroportin, an iron exporter, and induces the degradation of ferroportin $[39,40]$. The degradation of ferroportin leads to the inhibition of iron transport and a decrease of iron in circulation due to iron retention within the macrophage, which results in anemia of inflammation [40]. In concordance with our results, a cross-sectional study from the data of a 2003-2004 National Health and Nutrition Examination Survey in the US found that heavier female adolescents (BMI $\geq 85$ th percentile) aged 12-17 years had a higher prevalence of iron deficiency $(30.8 \%$ vs. $14.0 \%, p=0.003)$ compared to those with normal weight status (5th percentile $\leq \mathrm{BMI}<85$ th percentile) [41]. However, dietary iron intake was not significantly different between heavier and normal weight female adolescents (median: 12.10 vs. $13.40 \mathrm{mg} / \mathrm{d}, p=0.296$ ) [41]. Therefore, even with adequate iron intake, overweight or obese individuals with excess body fat appeared to have a higher risk of developing iron deficiency anemia [41].

\subsection{Dietary Pattern and Anemia}

Our study identified the anemia-inflammation-related dietary pattern is characterized by higher consumption of eggs, meat, organ meats, rice or flour products, fried rice or flour, sugary beverages, fried foods, and processed foods, but lower intakes of vegetables and fruits. In the multivariable logistic regression model, this dietary pattern was significantly associated with an increased risk of anemia and worse anemia-related biomarkers. The characteristics of the anemia-inflammation-related dietary pattern were similar to those of the Western dietary pattern, including high intakes of meat, processed meat, refined grains, fried foods, and sugary foods [42]. A cross-sectional study showed that the Western pattern was correlated with increased prevalence ratios (PR) of anemia (girls: $\mathrm{PR}=1.24$, $95 \%$ CI 1.06, 1.45) and being overweight/obese (boys and girls: PR $=1.15,95 \%$ CI 1.08, 1.21) in Mexican adolescents aged 12-19 years [43]. Additionally, a previous study performed with Thai girls aged 13-15 years reported that $85.5 \%$ students consumed dietary iron at $<67 \%$ of the Recommended Daily Allowance, and most students ate fewer green vegetables and fruits with their meal and drank more sweetened juice [44]. The Western dietary pattern has been shown to have inflammatory effects, according to the previous study by Kurniawan et al. [14]. The inflammatory dietary pattern, with high intakes of eggs, meat, preserved/processed foods, and sugary beverages, but low intakes of grains, vegetables, and fruits, was associated with an increased risk of anemia by $28-47 \%$ in middle-aged 
and older Taiwanese adults with impaired kidney function [14]. High adherence to the Western dietary pattern, and the status of being overweight or obese, could be associated with low-grade inflammation, which leads to a higher incidence of anemia. In agreement with our study, the anemia-inflammation-related dietary pattern and excess adiposity were positively correlated with an increased risk of anemia.

Our study observed a positive correlation between the anemia-inflammation-related dietary pattern and inflammatory biomarkers, such as WBC and CRP. Anemic subjects had a higher WBC count than non-anemic subjects, but CRP levels were not significantly different between anemic and non-anemic subjects. Similarly, the RRR-derived, or partial least squares regression-derived, Western dietary pattern, commonly characterized by high intakes of fried foods, processed foods, and sugary beverages, but low intakes of vegetables, fruits, and soup, was positively associated with CRP levels ( $r=0.39$ or $r=0.32)$ in nonmenopausal women aged 42-52 years [45]. Moreover, chronic obstructive pulmonary disease (COPD) patients with anemia had significantly higher CRP levels compared with the control subjects or those without anemia (both $p<0.001$ ) [46]. The association between $\mathrm{Hb}$ and CRP was also significantly negative in all COPD patients $(r=-0.28, p<0.01)$ [46]. Patients with iron deficiency anemia had higher CRP levels compared to those with pernicious anemia [46]. These findings indicated that CRP as an inflammatory marker was inversely correlated with $\mathrm{Hb}$, and might be a predictor for the risk of anemia.

In addition, the "sweet tooth" dietary pattern, characterized by a high consumption of sweetened beverages, milk, and cake, was more likely to increase the prevalence of anemia [47]. The highest quartile (Q4) of the "sweet tooth" dietary pattern increased the odds of anemia in men (OR $=2.34,95 \%$ CI 1.47, 3.73, $p<0.001)$ and women $(\mathrm{OR}=2.02$, $95 \%$ CI 1.31, 3.13, $p=0.002$ ) compared to the lowest quartile (Q1) of the dietary pattern [45]. The possible mechanism for the association of dietary pattern and anemia, particularly iron deficiency anemia, could be correlated with the effects of dietary components on the absorption or bioavailability of iron [47]. The bioavailability of iron depends on several factors, including the form of iron (heme vs. non-heme iron), the amount of iron in the diet, the presence of iron enhancers or inhibitors in the diet, and iron status in the individual [48]. Eggs inhibits non-heme iron absorption [49], and rice high in phytate (1.85-9.63 g/kg rice) [50] inhibits iron absorption by chelating with iron [51]. However, meat has some beneficial roles in iron homeostasis, not only due to its heme content but, also, as an enhancer for non-heme iron absorption [47]. Although the dietary pattern derived in our study was high in meat and organ meats, the presence of certain other food groups, such as eggs and rice, in this dietary pattern may interfere with iron absorption or bioavailability.

\subsection{Strengths and Limitations}

The current study has several strengths. To the best of our knowledge, this is the first study to investigate the associations between a dietary pattern determined by an RRR method and anemia-related inflammation in Taiwanese adults. A dietary pattern is a new approach for evaluating eating patterns in the general population [13]. The use of an RRR to derive the dietary pattern provides a better explanation for diet-disease associations [24]. Additionally, our study highlighted the correlation of several variables, including dietary pattern, lifestyle, and anthropometric data, with anemia. Furthermore, we had a large study population that may generalize the results at a greater scale.

In the present study, a number of limitations should be considered. First, it was limited by its cross-sectional study design, which cannot determine a causal relationship. Second, there was a possibility that the use of self-reported questionnaires could lead to misreporting food consumption. Third, the RRR method, even as a complimentary approach with a better reflection of diet and its relationship to diseases, requires response variables (such as biomarkers) in the regression model, which may not completely reflect the current state of knowledge. Indeed, there are still possibly undiscovered parameters as response variables, which may be associated with anemia. Fourth, we only defined 
anemia generally, according to WHO criteria, in this study, but cannot identify the type of anemia from the original database. Finally, our study had adjusted the results with classic confounders, but there are still some potential confounders, such as altitude, economic status, and mineral and vitamin intake, which can be considered in the future study.

\section{Conclusions}

The RRR-derived dietary pattern, characterized by high intakes of eggs, meat, organ meats, rice or flour products, fried foods, sugary beverages, and processed foods, was associated with an increased risk of anemia. Moreover, the highest tertile of the anemiainflammation-related dietary pattern was more likely to decrease $\mathrm{Hb}, \mathrm{Hct}$, and $\mathrm{RBC}$ levels but increase WBC and CRP levels compared to the lowest tertile of the dietary pattern. Current smoking was correlated with increased anemia and inflammatory biomarkers. However, alcohol drinking was associated with decreased $\mathrm{Hb}$ and RBC. Short sleep duration $(<6 \mathrm{~h})$ was correlated with decreased $\mathrm{Hb}$ but increased WBC. Inactive physical activity $(\leq 2 \mathrm{~h}$ /week) was associated with reduced anemia biomarkers but elevated inflammatory biomarkers. Our study also suggested that abnormal weight status was correlated with an increased risk of anemia and decreased anemia biomarkers, but increased inflammatory biomarkers.

Author Contributions: Conceptualization, R.P. and J.C.-J.C.; data curation, C.-Y.H. and H.-A.L.; data analysis, R.P. and A.L.K.; writing-original draft preparation, R.P. and J.C.-J.C.; writing-review and editing, L.-Y.L. and J.C.-J.C.; supervising, C.-Y.H. and J.C.-J.C. All authors have read and agreed to the published version of the manuscript.

Funding: This research received no external funding.

Institutional Review Board Statement: The study was approved by the Taipei Medical UniversityJoint Institutional Review Board (TMU-JIRB) no. 201907025.

Informed Consent Statement: All subjects signed the consent form authorized by the Mei Jau Health Management Institution.

Data Availability Statement: The data that support the findings of this study are available from the Mei Jau Health Management Institution, but restricted for research use only. The data are not publicly available.

Acknowledgments: We gratefully acknowledge the Mei Jau Health Management Institution for collecting and providing their database available for our study.

Conflicts of Interest: The authors declare no conflict of interest.

\section{References}

1. Wang, X.; Wu, Z.; Chen, Y.; Zhu, J.; Dong, X.; Fu, C.; Jiang, Q. Increased prevalence and incidence of anemia among adults in transforming rural China: Two cross-sectional surveys. BMC Public Health 2015, 15, 1302. [CrossRef]

2. World Health Organization. Haemoglobin Concentrations for the Diagnosis of Anaemia and Assessment of Severity; World Health Organization: Geneva, Switzerland, 2011.

3. Stevens, G.A.; Finucane, M.M.; De-Regil, L.M.; Paciorek, C.J.; Flaxman, S.R.; Branca, F.; Peña-Rosas, J.P.; Bhutta, Z.A.; Ezzati, M.; Nutrition Impact Model Study Group (Anaemia). Global, regional, and national trends in haemoglobin concentration and prevalence of total and severe anaemia in children and pregnant and non-pregnant women for 1995-2011: A systematic analysis of population-representative data. Lancet Glob. Health 2013, 1, e16-e25. [CrossRef]

4. Mengesha, M.B.; Dadi, G.B. Prevalence of anemia among adults at Hawassa University referral hospital, Southern Ethiopia. BMC Hematol. 2019, 19, 1. [CrossRef] [PubMed]

5. Le, C.H. The Prevalence of anemia and moderate-severe anemia in the US population (NHANES 2003-2012). PLoS ONE 2016, 11, e0166635. [CrossRef] [PubMed]

6. Mugisha, J.O.; Baisley, K.; Asiki, G.; Seeley, J.; Kuper, H. Prevalence, types, risk factors and clinical correlates of anaemia in older people in a rural Ugandan population. PLoS ONE 2013, 8, e78394. [CrossRef] [PubMed]

7. Pan, W.H.; Wu, H.J.; Yeh, C.J.; Chuang, S.Y.; Chang, H.Y.; Yeh, N.H.; Hsieh, Y.T. Diet and health trends in Taiwan: Comparison of two nutrition and health surveys from 1993-1996 and 2005-2008. Asia Pac. J. Clin. Nutr. 2011, 20, 238-250. [PubMed]

8. Khan, Z.A.; Khan, T.; Bhardwaj, A.; Aziz, S.J.; Sharma, S. Underweight as a risk factor for nutritional anaemia-a cross-sectional study among undergraduate students of a medical college of Haryana. Indian J. Community Health 2018, 30, 63-69. 
9. Mast, A.E.; Steele, W.R.; Johnson, B.; Wright, D.J.; Cable, R.G.; Carey, P.; Gottschall, J.L.; Kiss, J.E.; Simon, T.L.; Murphy, E.L.; et al. Population-based screening for anemia using first-time blood donors. Am. J. Hematol. 2012, 87, 496-502. [CrossRef]

10. Kim, H.; Shin, C.; Baik, I. Associations between lifestyle factors and iron overload in Korean adults. Clin. Nutr. Res. 2016, 5, 270-278. [CrossRef]

11. Jackowska, M.; Kumari, M.; Steptoe, A. Sleep and biomarkers in the English Longitudinal Study of Ageing: Associations with C-reactive protein, fibrinogen, dehydroepiandrosterone sulfate and hemoglobin. Psychoneuroendocrinology 2013, 38, 1484-1493. [CrossRef]

12. Liu, X.; Song, Q.; Hu, W.; Han, X.; Gan, J.; Zheng, X.; Wang, X.; Wu, S. Night sleep duration and risk of incident anemia in a Chinese population: A prospective cohort study. Sci. Rep. 2018, 8, 3975. [CrossRef]

13. Zhang, F.; Tapera, T.M.; Gou, J. Application of a new dietary pattern analysis method in nutritional epidemiology. BMC Med. Res. Methodol. 2018, 18, 119. [CrossRef]

14. Kurniawan, A.L.; Hsu, C.Y.; Rau, H.H.; Lin, L.Y.; Chao, J.C.J. Inflammatory dietary pattern predicts dyslipidemia and anemia in middle-aged and older Taiwanese adults with declined kidney function: A cross-sectional population study from 2008 to 2010. Nutrients 2019, 11, 2052. [CrossRef] [PubMed]

15. Xu, X.; Hall, J.; Byles, J.; Shi, Z. Dietary pattern, serum magnesium, ferritin, C-reactive protein and anaemia among older people. Clin. Nutr. 2017, 36, 444-4451. [CrossRef] [PubMed]

16. Chin, C.C.; Kuo, Y.H.; Yeh, C.Y.; Chen, J.S.; Tang, R.; Changchien, C.R.; Wang, J.Y.; Huang, W.S. Role of body mass index in colon cancer patients in Taiwan. World J. Gastroenterol. 2012, 18, 4191. [CrossRef] [PubMed]

17. Verma, M.; Rajput, M.; Sahoo, S.S.; Kaur, N.; Rohilla, R. Correlation between the percentage of body fat and surrogate indices of obesity among adult population in rural block of Haryana. J. Family Med. Prim. Care 2016, 5, 154-159. [CrossRef]

18. McLean, E.; Cogswell, M.; Egli, I.; Wojdyla, D.; De Benoist, B. Worldwide prevalence of anaemia, WHO vitamin and mineral nutrition information system, 1993-2005. Public Health Nutr. 2009, 12, 444-454. [CrossRef] [PubMed]

19. Lyu, L.C.; Lin, C.F.; Chang, F.H.; Chen, H.F.; Lo, C.C.; Ho, H.F. Meal distribution, relative validity and reproducibility of a meal-based food frequency questionnaire in Taiwan. Asia Pac. J. Clin. Nutr. 2007, 16, 766-776.

20. MJ Group. MJ Health Screening Center Questionnaire QR-121-1 MJ2011.06-1104TW. Available online: https://www.mjlife.com/ index.aspx?lang=chi\&fn=index (accessed on 3 August 2020).

21. Muga, M.A.; Owili, P.O.; Hsu, C.Y.; Rau, H.H.; Chao, J.C.J. Association between dietary patterns and cardiovascular risk factors among middle-aged and elderly adults in Taiwan: A population-based study from 2003 to 2012. PLoS ONE 2016, 11, e0157745. [CrossRef] [PubMed]

22. Nettleton, J.A.; Steffen, L.M.; Ni, H.; Liu, K.; Jacobs, D.R., Jr. Dietary patterns and risk of incident type 2 diabetes in Multi-Ethnic Study of Atherosclerosis (MESA). Diabetes Care 2008, 31, 1777-1782. [CrossRef] [PubMed]

23. Meyer, K.A.; Sijtsma, F.P.; Nettleton, J.A.; Steffen, L.M.; Van Horn, L.; Shikany, J.M.; Gross, M.D.; Mursu, J.; Traber, M.G.; Jacobs, D.R., Jr. Dietary patterns are associated with plasma F2-isoprostanes in an observational cohort study of adults. Free Radic. Biol. Med. 2013, 57, 201-209. [CrossRef]

24. Kurniawan, A.L.; Hsu, C.-Y.; Lee, H.-A.; Rau, H.-H.; Paramastri, R.; Syauqy, A.; Chao, J.C.J. Comparing two methods for deriving dietary patterns associated with risk of metabolic syndrome among middle-aged and elderly Taiwanese adults with impaired kidney function. BMC Med. Res. Methodol. 2020, 20, 255. [CrossRef] [PubMed]

25. Batis, C.; Mendez, M.; Gordon-Larsen, P.; Sotres-Alvarez, D.; Adair, L.; Popkin, B. Using both principal component analysis and reduced rank regression to study dietary patterns and diabetes in Chinese adults. Public Health Nutr. 2016, 19, 195-203. [CrossRef]

26. Hisa, K.; Haruna, M.; Hikita, N.; Sasagawa, E.; Yonezawa, K.; Suto, M.; Ota, E. Prevalence of and factors related to anemia among Japanese adult women: Secondary data analysis using health check-up database. Sci. Rep. 2019, 9, 17048. [CrossRef]

27. Sandhya, M.; Satyanarayana, U.; Mohanty, S.; Basalingappa, D.R. Impact of chronic cigarette smoking on platelet aggregation and coagulation profile in apparently healthy male smokers. Int. J. Clin. Exp. Physiol. 2015, 2, 128-133.

28. Waseem, S.M.A.; Alvi, A.B. Correlation between anemia and smoking: Study of patients visiting different outpatient departments of Integral Institute of Medical Science and Research, Lucknow. Natl. J. Physiol. Pharm. Pharmacol. 2020, 10, 149-154. [CrossRef]

29. Nordenberg, D.; Yip, R.; Binkin, N.J. The effect of cigarette smoking on hemoglobin levels and anemia screening. JAMA 1990, 264, 1556-1559. [CrossRef]

30. Sharma, A.J.; Addo, O.Y.; Mei, Z.; Suchdev, P.S. Reexamination of hemoglobin adjustments to define anemia: Altitude and smoking. Ann. N. Y. Acad. Sci. 2019, 1450, 190-203. [CrossRef]

31. Pollini, G.; Maugeri, U.; Bernardo, A.; Bianchi, I.; Flak, E.; Jedrychowski, W. Erythrocytes parameters due to aging, smoking, alcohol consumption and occupational activity in a working population of petrochemical industry. The Pavia Study. G. Ital. Med. Lav. 1989, 11, 237-240.

32. Lewis, G.; Wise, M.P.; Poynton, C.; Godkin, A. A case of persistent anemia and alcohol abuse. Nat. Clin. Pract. Gastroenterol. Hepatol. 2007, 4, 521-526. [CrossRef]

33. Berad, A.; Chand, V. Study to compare hematological parameters in alcoholic and non-alcoholic individuals. Natl. J. Physiol. Pharm. Pharmacol. 2019, 9, 1176-1179. [CrossRef]

34. Ballard, H.S. The hematological complications of alcoholism. Alcohol Health Res. World 1997, 21, 42-52. [CrossRef]

35. Kandasamy, K.; Prasad, A.; Surendran, A.; Sebastian, A.C.; Rajagopal, S.S.; Ramanathan, S. Epidemiological study of prevalence of anemia and associated risk factors in a rural community; a home-based screening. Asian J. Pharm. Clin. Res. 2017, 10, 307-309. 
36. Nishida, T.; Sakakibara, H. Low lymphocyte count in underweight Japanese women. Environ. Health Prev. Med. 2008, 13, 345-348. [CrossRef] [PubMed]

37. Sumarmi, S.; Puspitasari, N.; Handajani, R.; Wirjatmadi, B. Underweight as a risk factor for iron depletion and iron-deficient erythropoiesis among young women in rural areas of East Java, Indonesia. Malays. J. Nutr. 2016, 22, $219-232$.

38. González-Domínguez, Á.; Visiedo-García, F.M.; Domínguez-Riscart, J.; González-Domínguez, R.; Mateos, R.M.; Lechuga-Sancho, A.M. Iron metabolism in obesity and metabolic syndrome. Int. J. Mol. Sci. 2020, 21, 5529. [CrossRef] [PubMed]

39. Fleming, R.E. Iron and inflammation: Cross-talk between pathways regulating hepcidin. Int. J. Mol. Med. 2008, 86, 491-494. [CrossRef]

40. Ganz, T.; Nemeth, E. Iron imports. IV. Hepcidin and regulation of body iron metabolism. Am. J. Physiol. Gastrointest. Liver Physiol. 2006, 290, G199-G203. [CrossRef]

41. Tussing-Humphreys, L.M.; Liang, H.; Nemeth, E.; Freels, S.; Braunschweig, C.A. Excess adiposity, inflammation, and irondeficiency in female adolescents. J. Am. Diet. Assoc. 2009, 109, 297-302. [CrossRef]

42. Paterson, E.N.; Neville, C.E.; Silvestri, G.; Montgomery, S.; Moore, E.; Silvestri, V.; Cardwell, C.R.; MacGillivray, T.J.; Max-well, A.P.; Woodside, J.V.; et al. Dietary patterns and chronic kidney disease: A cross-sectional association in the Irish Nun Eye Study. Sci. Rep. 2018, 8, 6654. [CrossRef]

43. Zárate-Ortiz, A.G.; Melse-Boonstra, A.; Rodríguez-Ramírez, S.; Hernández-Cordero, S.; Feskens, E.J.M. Dietary patterns and the double burden of malnutrition in Mexican adolescents: Results from ENSANUT-2006. Nutrients 2019, 11, 2753. [CrossRef]

44. Hayeemad, S.; Pradipasen, M.; Satheannoppakao, W.; Kaseamsub, R. Dietary Pattern and Factors Associated with Anemia among Female Adolescents in Islam Private Schools. In Proceedings of the 2nd International Conference on Humanities and Social Sciences, Prince of Songkla University, Hat Yai, Thailand, 10 April 2010; Available online: http:/ / fs.libarts.psu.ac.th/research/ conference/proceedings-2/8pdf/001.pdf (accessed on 3 August 2020).

45. Wang, D.; Karvonen-Gutierrez, C.A.; Jackson, E.A.; Elliott, M.R.; Appelhans, B.M.; Barinas-Mitchell, E.; Bielak, L.F.; Huang, M.H.; Baylin, A. Western dietary pattern derived by multiple statistical methods is prospectively associated with subclinical carotid atherosclerosis in midlife women. J. Nutr. 2020, 150, 579-591.

46. Hasanefendić, B.; Hajrović, A.; Begović, E.; Uzunalić, H. The Ratio of Hematological Parameters and Markers of Inflammation in Patients with Iron Deficiency and Pernicious Anemia. In Proceedings of the International Conference on Medical and Biological Engineering; Springer: Berlin, Germany, 2017; pp. 769-773.

47. Shi, Z.; Hu, X.; Yuan, B.; Pan, X.; Dai, Y.; Holmboe-Ottesen, G. Association between dietary patterns and anaemia in adults from Jiangsu Province in Eastern China. Br. J. Nutr. 2006, 96, 906-912. [CrossRef] [PubMed]

48. Boccio, J.R.; Iyengar, V. Iron deficiency: Causes, consequences, and strategies to overcome this nutritional problem. Biol. Trace Elem. Res. 2003, 94, 1-32. [CrossRef]

49. López, M.A.; Martos, F.C. Iron availability: An updated review. Int. J. Food Sci. Nutr. 2004, 55, 597-606. [CrossRef]

50. Matsunaga, A.; Yamamoto, A.; Mizukami, E. Determination of phytic acid in various foods by indirect photometric ion chromatography. Food Hygiene Safety Sci. 1988, 29, 408-412. [CrossRef]

51. Kito, A.; Imai, E. The Association with dietary patterns and risk of anemia in Japanese elderly. J. Nutr. Sci. Vitaminol. 2020, 66, 32-40. [CrossRef] 